\title{
PERSPECTIVES
}

\section{Female genital mutilation (FGM) in Somaliland - why is change so slow?}

\author{
Annika Johansson ${ }^{a}$, Abdirahman Osman Gaas ${ }^{b}$, Amina Mahmoud Warsame ${ }^{b}$

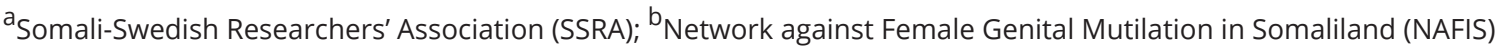

\begin{abstract}
Female genital mutilation (FGM) is defined as any procedure involving the alteration or excision of external female genitalia for no medical reason. Somaliland has among the highest prevalence rates of FGM globally. In this article we describe how the Civil Society Organisation (CSO) 'Network against female genital mutilation in Somaliland' (NAFIS) has approached the challenge to reduce the high FGM prevalence. From its start in 2006, NAFIS has developed a multifaceted program to reach the overall goal: the elimination of all forms of FGM in Somaliland.
\end{abstract}

Alone among the group of CSOs in the network, NAFIS introduced in its activities medical care and counselling for women who suffer from the consequences of FGM. From 2011 and onwards, thousands of women have been relieved of their FGM-related health complications and participated in counselling sessions at project centres. Shortly after this visit they have been invited to participate in community group meetings to share their experiences with other women who also have received FGM care and counselling, and other community members.

The aim of the article is to describe this model of work - combining FGM care and counselling with community dialogues. The article is basically descriptive, using the authors' own observations and encounters with project clients and staff over eight years. We have also used findings from three Master's theses on aspects of the process, and from other small scale studies to highlight people's understanding, experiences and opinions in a context of an on-going health intervention.

A lesson learnt from NAFIS project is that it has helped to open up communicative spaces in community dialogues where experiences are shared and understanding created of the harm caused by FGM, without the habitual stigma and shame. We discuss this process in a context of behavioural change theories. A major challenge during the process has been to involve men in the project's FGM information and counselling activities. The role of nurses/midwives, being the first to meet women with FGM complications, is also discussed and the need emphasised to strengthen capacity of this category of health workers. One type of FGM gaining in usage is the poorly defined sunna, the health risks of which are unclear.
ARTICLE HISTORY

Received 5 Dec 2020

Accepted 6 May 2021

RESPONSIBLE EDITOR

Lennart Freij

KEYWORDS

Female genital mutilation, counselling and care, community dialogues, Somaliland.

\section{Background}

Female genital mutilation, FGM, is defined as a practice that involves the partial or total removal of external female genitalia or other injury to female genital organs for non-medical reasons. FGM is currently practiced in 31 countries, most African and in some parts of the Middle East and Asia. It is estimated that more than 200 million girls and women alive today have undergone FGM [1].

In 2018 the UN General Assembly adopted the resolution 'Intensifying global efforts for the elimination of female genital mutilation' [2] in line with the Sustainable Development Goals. Using lifetime analysis of risks of being exposed to FGM in countries where it is practiced, a recent study showed that the overall likelihood of experiencing FGM had decreased during the last four decades in several countries. However, progress had been very uneven and in certain countries almost no change was seen. The conclusion was: "Based on current trends, the goal of eliminating FGM by 2030 is out of reach"[3]. (Most of the 28 countries analysed were in Africa).

Among the populations in Africa where FGM is practiced, the highest prevalence rates are found in Somaliland at the Horn of Africa. Campaigns against 
FGM have been implemented there for nearly four decades but change has been very difficult to attain. A UNICEF Multiple Indicator Cluster Survey [4] carried out in Somaliland in 2011, reported a prevalence rate of 99\% among women 15 to 49 years, with the pharaonic type as the most common. An equally high prevalence rate was found in a population based survey carried out in 2014 [5]. In a follow-up survey five years later in the same area and age group, prevalence was $98-99 \%$ but the sunna now comprised one third of the cases. The Somaliland Health and Demographic Survey (SLHDS) from 2020 [6] showed the same high FGM prevalence while also here the sunna had increased to one third of the cases [5]. It was most popular among urban dwellers and among the more educated, while the pharaonic type dominated among rural and nomadic groups.

WHO has classified FGM into four main types [7] but in Somaliland people commonly refer only to two of these types: (a) sunna, the partial or total removal of the clitoris and labia minora, with or without excision of the labia majora; and (b) infibulation, often called pharaonic, which is a more drastic operation, narrowing of the vaginal orifice by cutting and bringing together the labia minora and/or the labia majora to create a type of seal, with or without excision of the clitoris. In most instances, the cut edges of the labia are stitched together (infibulated). In this article we refer only to the sunna and the pharaonic type.

Traditionally, in Somaliland, FGM was held to be a religious obligation, but several well-known religious leaders in Somaliland have pronounced themselves against FGM because of the increasing evidence of its health risks [8]. In a religious Fatwa from the Ministry of Religious Affairs from 2018, it was proclaimed that if parents circumcise their daughters, it should be done with great care to avoid any risky procedure causing harm for the girl [9]. The pharaonic procedure was declared forbidden while the sunna was mentioned as acceptable. The Fatwa does not explain what is meant by sunna, but it prohibits any cutting or stitching. Punishments for causing any harm to girls and women should be imposed on the person responsible for this. No punishments have as yet been imposed according to NAFIS.

The problem with the Fatwa is that it left to parents and the circumcisers to define what is a risky procedure. Although the sunna defined by most religious clerics in Somaliland usually equates to WHO's FGM type 1 [7], the cut in its mildest form, this is not spelt out clearly in the Fatwa. Consequently, the understanding of sunna is not well defined among people; it may mean anything from a drop of blood obtained from the clitoris, or it may mean the removal of the clitoris, partially or totally, followed by two stitches. In a qualitative study on people's understanding of the sunna, many women declared that they could not describe what the sunna involved, they only knew that it was not the pharaonic type [10]. In an interview study on people's attitudes towards FGM, an FGM-activist was quoted:
There are no people who are trained for doing sunna circumcision. The same people who used to do the pharaonic are also doing the sunna. They cut all the parts that they used to cut in the pharaonic. The only difference is whether they suture less or not [11].

Due to the lack of consensus among key religious groups, and also among some CSOs, a law for zero tolerance of FGM has not yet been possible to get acceptance for by the Somaliland parliament. Of the 28 countries in Africa with a tradition of FGM, 23 countries had legislated against FGM in 2021. Somaliland is currently without such legislation [12].

A strong voice in Somaliland for the zero tolerance of FGM is the 'Network against female genital mutilation in Somaliland', NAFIS, a CSO established in 2006 as an umbrella organization for some $20 \mathrm{CSO}$ working to achieve the goal to eradicate FGM. Learning from previous national and international anti-FGM strategies, NAFIS from the start developed a program including advocacy for human rights, gender equality and the rights of girls and women to physical integrity. As the coordinator of national CSOs against FGM, NAFIS has been actively involved in advocacy at Government level, including among the religious leaders, for legislation against FGM. Education and information about FGM is communicated through schools, civil organisations and community groups, and in mass media. Integration of FGM messages into NAFIS rural development projects is another way to spread information about the Fatwa and raise awareness of the rights of girls and women to physical integrity. Since 2011 NAFIS has introduced FGM counselling and medical care in its activities for women who suffer from its consequences, the only CSO in Somaliland to do so.

The aim of this article is to describe how NAFIS, in coordination with the public health services, developed its interventions of combining FGM counselling and care with active community dialogues The article is basically descriptive, using the authors' own observations and encounters with project clients and staff over several years, information from three Master's theses which the first and third authors of this article have supervised, documented project activities and other small scale studies to highlight experiences in a context of an ongoing health intervention.

\section{NAFIS' strategy for mobilizing against FGM}

Among NAFIS board members were from the start also midwives, who through years of clinical practice had observed the many serious complications of FGM throughout women's lives. They had met young girls brought by their mothers to get help for genital infections, menstrual problems and the development of cysts. They had also met young wives brought to the clinic to be cut open for their husbands at marriage, as well as women in labour, coming to the clinic to widen the passage for the child about to be born, with higher risk of neonatal death [8], and older women suffering from constant untreated 
FGM complications, the causes of which they ignored. They had found that women were very shy and ashamed to talk about these problems and had previously had no one to ask for advice and help.

\section{The first Support Centre}

At that time in the capital Hargeisa, there were already some such services, notably the Edna Adan Maternity Hospital, established in 2002. It is a pioneering institution for maternal health care, training and research, specialised also on FGM, receiving many girls and women with FGM complications [13]. However, there were many poor, marginalized women in the city at that time living in camps for internally displaced people (IDP). Through a Swedish based CSO, the Somali-Swedish Researchers' Association (SSRA), funding was secured to set up a Support Centre (SC) for women with FGM complications. It was established in 2011 in an area inhabited mainly by IDPs in the outskirts of town. It was located in the small Magan Hospital as part of its maternal and child health (MCH) clinic, staffed by two qualified midwives trained by NAFIS to manage minor FGM complications. At the SC women got care for FGM-related problems, together with counselling on how to protect their health and that of their children. Women with serious complications were referred to one of the two hospitals in Hargeisa with FGM-related care or in exceptional cases to Addis Ababa.

To learn more about the centre's clientele, two Swedish Master's Students were invited to carry out studies with women attending the SC and with the centre midwives. A Somali social scientist conducted qualitative interviews with ten women in each of these two studies. The first study focused on women seeking care for FGM-related problems [14] and the second dealt with the midwives' experiences of counselling the women [15]. The findings indicated that none of the women diagnosed with severe complications of the pharaonic cutting in childhood, had understood the causes of their problems and had not dared to ask anyone for advice where to seek help. They thought that what they suffered from was normal for all women, at least for all Moslem women. FGM, they explained, was a sign of being a Moslem woman, different from a Western woman. The study author concluded that:

\footnotetext{
"the most significant theme emerging from the interviews was how increased knowledge of the harmful effects of infibulation had profoundly influenced the women's change of attitude towards this practice" [14].
}

The Centre midwives had themselves all been subjected to the pharaonic procedure. Asked if this affected their counselling, they said that they found it to be an advantage:

'I tell the women that I am like them and understand their problems. Since some of them are very shy, they feel confident when I tell them that [15].

However, some of the midwives also found it difficult at times to counsel the women. They were sometimes explained that FGM is a part of culture and they, the midwives, should not interfere in family affairs and subvert Somali culture [15]. In both studies most of the women interviewed declared that they, having now understood the cause of their suffering, would not have FGM done on their daughters.

\section{'I don't expect I will ever circumcise my daughter. I do not care if she can find a husband or not. I do not want her to have my experiences' [14].}

The women were asked who in the family was most influential in deciding over if a daughter should be circumcised and if so, with what type of FGM. Most of the women agreed that the mother of the girl was usually the main decision maker, often supported, or pushed, by her own mother. The fathers could have the final say if there was disagreement in the family [15].

When informing about the new SC in the community, it was made clear that men were also very welcome to attend. However, only few men came for the counselling and education sessions, sometimes together with their wives, sometimes by themselves. In an interview with the male health assistant at the SC, he expressed his concern over the lack of knowledge among the men:

\begin{abstract}
On the wedding night, the woman is expected to be happy but she is worried. This is a problem for the couple. She has to be cut open and this is terribly painful. The young men are not informed, they don't know what to expect. Therefore, the men should be informed and they can also talk to other men. They can at least convince their families not to circumcise their daughters.
\end{abstract}

\section{Reaching out to the community}

The SC staff at Magan Hospital had regular contact with community groups in the area around the Centre, such as the Village Committee, the Health Committee and the local Women's Union, to explain the aim of the SC and to ask them to refer women and couples in need. Monthly community group meetings were also organized with women who had recently attended the SC. The venue was often a woman's home or outside in a quiet place. A midwife from the Centre gathered a group of around 20 women, willing to participate in the group discussion. Moderated by the midwife, the participants were encouraged to share their views on and experiences of FGM. We were invited to one such meeting and could observe the intensity of the discussion.

Below are selected parts of the audiotaped group discussion [16]. It started with a young woman, Asia (not her real name), who had just declared that she was preparing her daughter for the pharaonic cut.

One woman asked:

But why, Asia, why do you want to circumcise your daughter?

\section{Asia explained:}

To keep her clean and protect her from pregnancies.... A girl who is stitched together is different from a girl who is not.... closed girl is more respected, she has higher status and her mother feels proud of her...An open girl is looked down upon and her mother too.

Some of the women agreed with Asia, fearing that 
leaving a girl 'open' would lead to ridicule and stigmatization from others:

The female neighbours who are told about an un-cut woman will always laugh and wonder what her genitals look like without cutting. Many see it as unnatural to be left un-cut....People will call an uncircumcised woman names, calling her 'open', not a virgin, and she will be suspected of immorality.

Another woman was worried about the safety of an 'open' girl:

If my daughter is left open, without the preventive stitches, how can she be protected?

This statement gave rise to a vivid exchange of opinions. Some argued against the belief that stitching the girl together would protect her from pregnancies:

Also women who are closed can become pregnant. So if we know that infibulation is not preventing pregnancies, why make women suffer and injure their organs. Why do you want to create so much pain for your daughter?

Asia answered:

If only I could be sure that all other girls are relieved from being cut then I would also leave my girl without it.

After the meeting several women gathered around Asia, assuring her that her daughter would be fine without the stitches, as girls are no longer refused marriage for that reason. Then Asia said:

If you are sure, I will leave her like Allah made her.

In yet another lively group discussion a few weeks later, the midwife moderating the meeting told of her own experiences when circumcising little girls as a young midwife:

When we came to perform FGM the girls got so scared so they locked themselves up in the toilet. We had to force the door open. Other girls ran away and we had to catch them, just imagine how scared they were! I have grownup daughters and they also have daughters. I haven't done anything to them, they are not circumcised. Let the girls be free, leave them in peace!

In both group meetings, the two very charismatic women had taken the lead in guiding the discussions while allowing free speech.

The Centre had become well known in the area, and the shyness and shame around FGM had seemingly evaporated in the confidential talks between women and their counsellor. In the group meeting, the women's experiences from the Centre were still fresh in mind and the atmosphere was conducive to sharing with others. Combining counselling and care given at the SC, with active community dialogues became known as the project's new working model. In an interview, the director of the Support Centre summarized her impressions of the first years' project activities:

When they first came to the Centre the women were shy to talk, they felt ashamed about their problems. But in the group meetings they heard other women talking freely, so they also dared to speak. And when they understood the cause of their sufferings they said: 'Never my daughter!

The SC at Magan Hospital continued for several years; it became well known and attendance rates increased steadily, with the exception of one year when there was unrest in the IDP where the SC was located. As Magan was a private hospital its SC was later transferred to a public $\mathrm{MCH}$ clinic in Hargeisa. It then changed its name to Model Centre (MC).

\section{Expanding the project - moving into the pub- lic health sector}

Over the following years NAFIS, in close collaboration with the local and regional health authorities, developed a structure of extending the outreach of its Model Centres through a network of 'sister clinics' within the catchment area of the MCs. By 2020, five MCs in five regions of Somaliland had been established, all located within a public $\mathrm{MCH}$ clinic in the central town of each respective region. One of the public hospitals in each region was selected as referral hospital to which women with severe FGM complications should be referred for treatment. Thus, a referral chain from the 'sister' clinic, via the MC to reach the referral hospital, was created for women needing surgery or other advanced treatment for their FGM complications.

When MCs were established in the new regions, studies were conducted with adolescents and adult men and women separately, by nursing students from the area. In group interviews, people's knowledge about different types of FGM and their complications were explored [17]. The difference between adult men and women was striking. Men had heard about the pharaonic circumcision but could hardly mention any complications from it while the women knew a long list of complications. Some of the women also mentioned the trauma of being circumcised in childhood, which is rarely talked about, but for some, this traumatic memory had come back at the wedding night, which had ended in fear and fighting with their partners.

In another study from this area, two nurses, both Master's students at the University of Hargeisa, interviewed women attending the MCs about their attitudes and FGM plans for their daughters [18]. Emerging from the analysis was the intensity of pressures and diverging opinions the women had been exposed to from many persons; especially grandmothers were said to be strongly against any change in FGM practices. The local imam was said to advocate for the sunna which was also what one third of the interviewed women said they preferred. However, like in other studies referred to here $[10,11]$ few of the women interviewed could explain what the sunna type entailed. One woman commented: 'The sunni type is more or less the same cutting as the Pharaonic but they name it sunni' [18].

NAFIS supported the Somaliland Nursing and Midwifery Association (SLNMA) to develop a curriculum for nurse/midwifery students on skills in counselling and 
treatment of minor FGM complications, as well as a new curriculum for community health workers in basic FGM care and counselling. The MCs were assigned two midwives each, trained in FGM counselling and care using the new curricula. Forty $\mathrm{MCH}$ clinics/health posts were selected as links between the MCs and the communities for reaching out to those in greatest need the rural population and nomadic groups. The community group meetings continued within each district.

In November 2018 a workshop was held with officials from all levels of health administration to review the situation in Somaliland regarding management of FGM complications and discuss the possibility of integrating NAFIS model of work into the public health system. Among the major points raised was the present limited and sometimes total lack of competence in care and management of FGM complications among the health staff in the public health services. The urgent need for this competence was emphasized, as well as the need to reinforce the referral chain for women with severe FGM complications. NAFIS' training of health staff and interventions at the MCs for FGM care, counselling and community outreach, were considered highly relevant. A key message was that women with FGM complications should be gently supported to seek help from the FGM services, considering the stigma and shame which for long had been barriers for them to access services [19].

\section{Understanding the complexity of FGM behaviour change in social change}

Prevalence data are commonly taken as the indicator of changing FGM behaviour. As shown in several studies [20] self-reported information on issues which are sensitive and/or difficult to define often show low validity. The respondent may be shy to talk about FGM and just answers what she thinks is acceptable, or simply does not know which type of FGM she and/or her daughters have been subjected to [10]. Important information on changing FGM practices may thereby be lost or misinterpreted. The samples, usually drawn from clinical settings, are not representative for the general population. The large scale FGM prevalence surveys regularly performed by international organisations may also suffer from weaknesses of data validity and representativeness, but their results are usually accepted as indicators of general trends.

In studies of change of social conventions like FGM, deeply rooted in culture, the fear of being alone in breaking the convention is typically a very strong barrier for any change. In the group discussion where Asia explained why she had decided to have the pharaonic cut done on her daughter, her strong fear was that her daughter would be looked down upon as an 'open', immoral girl if not stitched together. No man would want to marry her and she, her mother, would be looked down upon as well. In this case, we can see how her fear is closely intertwined with the concept of honour; an unmarried daughter having a sexual relation with a man is the worst of sins - she would spread shame over the whole family, she may even be rejected by the family. But the support of the women in the group assured Asia that she should have no fear; her daughter would not be stigmatized and ridiculed, as "many girls are now left as God made them'.

We don't know if Asia would stick to her decision not to have her daughter cut; that would depend on the number of families who decided the same. In the social convention theory [21] focus is on the individual as a member of a community. The notion of what is the 'critical mass' of a community group needed to accept to act together to abandon FGM, is discussed with reference to the Tostan Project in Senegal [22].

Another theoretical perspective applied in studies of social change is the theory of communicative action where participants reach agreement and mutual understanding about what to do in their particular practical situation [23]. Asia's decision to refrain from circumcising her daughter was reached after an hour and a half of lively discussion for or against FGM, where 'against' took the upper hand. In a study from Ethiopia, a similar strategy was used to encourage community dialogues, enabling community members to reflect on their own practices and hopefully reverse the social convention [24]. Another study from Somaliland also deals with the potentials to achieve FGM change through collective empowerment of community groups, involving also other important stake holders like religious leaders [25]. Based on a rich material of qualitative interviews and focus group discussions, the author notes the lack of conversations about FGM between community members and within the family, as told by a young man: 'we know only a little as it is never talked about with us'. Some had attended workshops or public meetings about FGM where they 'were told what to do and how to think, rather than invited to talk about what FGM meant to them and their families'. Based on the research findings the author suggests that interventions to change a practice like FGM are likely to be more effective through opportunities for dialogue and exchange than 'delivery of information' [25].

A challenge of interventions to achieve FGM behavioural change is to measure their impact. This is discussed in another article [26] in which the authors point out that many interventions are based on theoretical models of behaviour change and that there is a need to develop indicators which are appropriate to the change anticipated. As FGM is performed on an individual, usually within the confines of family, supported by community social norms and conventions, it is important to recognize the wider socio-cultural context in which FGM takes place and the values and decisions of others related to the practice. Multi-disciplinary approaches, combining quantitative and qualitative research design and following change processes over a sufficiently long period of time are needed when evaluating impact of an intervention.

A new initiative of NAFIS, based on the interventions 
described in this article, is a participatory research project named 'Ambassadors for change'. Over the years NAFIS has enabled thousands of women with serious FGM complications to get psychosocial and medical treatment, sometimes surgery. This experience, which the women often describe as having 'changed their lives' [27], is seen as a possible entry point for creative communication between women with different experiences and understanding of FGM. The project is bringing together 'FGM survivors' (defined here as women who have recovered from their FGM complications thanks to surgery or other treatment) with women having different FGM experiences. Men and other stakeholders are also invited in a participatory research process, to create understanding of the sufferings endured by the 'survivors' and jointly develop plans to end FGM in their own settings [28].

Eight years of high attendance at NAFIS' MCs in the regions, followed up in community dialogues, show the popularity of this model of work. Close contact has been maintained with local leaders and community groups to share information and experiences of the intervention process. The challenges met over the years are mainly of a practical nature, such as lack of money to pay for treatment and transport for poor women, low salary of the centre staff (who are since 2015 on Government payroll) and high expectations from clients for economic and other assistance (which they compare with more generous neighbouring CSO projects). These challenges are signs of the general poverty and underemployment in the areas where NAFIS has its MCs. A related challenge is the difficulty to involve men in the project's FGM-education and counselling activities. In one of the project reports this was explained: "The men are always in the market place or looking for jobs somewhere".

The nurses/midwives stand out as key agents for changing FGM practices by providing a practical answer to the harm created by it. However, the current capacity of the system is highly insufficient. In a recent study of the healthcare system of Somaliland, the authors note that little attention has been devoted to building capacity of healthcare workers to provide optimal care for women with FGM-related complications [29]. The findings were based on interviews with 20 health care providers in only one region and this may not reflect the overall situation in Somaliland. However, as the authors stress, most patients with FGM-related complications live in rural areas or in nomadic mobile settlements with under-resourced facilities and health providers often lacking the required training. Summarizing the findings the authors note: "Key knowledge gaps remain for both the prevention of FGM and evidence-based care to optimize health outcomes for cut girls and women".

\section{Concluding remarks and reflections}

We have followed NAFIS' intervention project against FGM, observed activities and discussed progress and challenges with project field staff and women attending the centres. Using findings from Master's theses, documented group dialogues and other small project studies, we have highlighted people's understanding, attitudes and plans for their own daughters with regard to FGM.

Through this learning process certain themes have emerged. The men's involvement in FGM-related activities and concerns seems erratic and unclear. They are invited to attend FGM counselling and information sessions, but very few come. Uninformed about the status of an infibulated woman they are not prepared for this when meeting their wives at the weeding nigh. Normally it is the mother or other female relatives who decide about a girls' circumcision, but when there is disagreement in the family, the father may take the final decision, although he is probably the person knowing least about its consequences. Between the norms of a patriarchal culture and the culturally constructed stigma and shame attached to genital organs and sexuality, the men's role and involvement are indeed complicated.

A related issue is the unclear understanding of the sunna. Described by the religious leaders as a harmless procedure with no risk for girls' and women's health, the potential risks of the sunna seems hidden behind a shield of religious acceptance. When a woman is advised by her local imam to have the sunna applied for her daughter, the myth of its harmlessness is reinforced. Bringing the girl to the traditional circumciser, the mother and/or grandmother will ask for a sunna, but none of them really knows what this involves. When asking what she should do, the circumciser may simply be told to 'do it well' which for her may mean 'same procedure as before but fewer stitches'.

Trust and dialogue between women and the health professionals who relieve them from their FGM complications, have proved to be a powerful tool to break the silence and dispel misunderstandings of what FGM is doing to girls and women. A huge challenge will be to break men's isolation from the realities of FGM and involve them in the struggle to end the practice as informed and emphatic partners of their wives and caring fathers of their daughter. Initiatives to include men in dialogues on the consequences of FGM are tried in NAFIS' project Ambassadors of Change [28]. Qualitative and clinical research could help to clarify the potential health risks of the various procedures commonly named sunna, which may be used as a euphemism for something more than 'just a small cut'.

The common health risks of FGM are well known. They compete with other very urgent health problems. But special for FGM is the profound violation it represents of the human rights of almost half of the population. Despite decades of mobilization and campaigns against FGM, Somaliland still has a persistently high rate of FGM, mostly pharaonic, while the less radical but poorly defined sunna is increasing. Why is change so slow?

In recent decades, Somaliland has gone through periods of war and repeated droughts leading to serious food 
shortages and large-scale displacement of its population.

Could the persistently high FGM prevalence in Somaliland be construed as a sign of societal insecurity? A sign of the poor people's insecurity over where and of what they will live during next drought, everybody's sense of insecurity about how long peace will prevail? Maybe the family will be separated and parents will lose control over their girls in huge camps for displaced people. Parents may feel that by circumcising ones daughters, they will at least be protected from immorality and rape and be sure to find a husband to care for them.

Research on conditions in refugee camps and other extreme situations has indicated that in periods of insecurity and chaos, the need to establish cultural and religious belonging and identity tends to be reinforced. Somali scholars have noted that FGM, a significant symbol of this belonging, showed a tendency to increase during the war in Somaliland in the 1990s. More recently, during the Covid19 pandemic in the early 2020s, it has been confirmed that the incidence of FGM has gone up $[30,31]$. It has been suggested that parents take the chance to have the cuts performed during school lock-down, allowing the girls' wounds to heal before schools open up. We suggest that the reasons may be multiple. Exploring FGM incidences and other forms of gender based violence in situations of population displacement and other insecure conditions is an important research lead, especially in fragile states where social security nets may easily crumble away.

Peace, poverty eradication, human rights and gender equality could be seen as the sine qua non for the total eradication of FGM. Since peace was established in the late 1990s, the Somaliland Government has taken laudable steps in this direction, notably in increasing the education of girls. When people can hope for a life in peace and progress, when women and men have equal rights, and everybody understands the harm created by FGM and its violation of the rights of women and girls to physical integrity, we believe that FGM will disappear. Legislation for the abandonment of FGM will help to speed up the process, as will the work of NAFIS and other interventions empowering communities to demand the rights of Somali girls and women.

\section{Summary in Somali}

\section{CINWAAN}

Gudniinka Gabdhaha ee Somaliland- Muxuu Isbeddelku u Gaabinayaa?

\section{SOOKOOBID}

Gudniinka Gabdhaha waxaa lagu qeexaa nidaam kasta oo ku lug leh wax ka beddelka ama goynta qaybta hore ee xubinta taranka haweenka iyadoo aanay jirin sababo caafimaad. Somaliland oo ku taalla geeska Africa ayaa ka mid ah goobaha ugu badan gudniinka gabdhaha ee dunida. Maqaalkaaan waxaannu ku qeexaynaa sida Ururka Bulshada Rayidka (UBR) ah ee Dalladda joojinta gudniinka gabdhaha ee NAFIS Network u wajaheen caqabaddan si loo yareeyo baahsanaanta gudniinka gabdhaha. Tan-iyo bilowgii 2006, NAFIS waxay samaysay barnaamijyo kala duwan si loo gaadho hadafka guud, loona cirib tiro dhammaan noocyada gudniinka gabdhaha ee Somaliland.

Iyadoo ka mid ah kooxda dalladda UBR ayey NAFIS ku soo dartay hawleheeda, hirgelinta daryeelidda caafimaad iyo talooyin loogu talo galay dumarka la-ildaran dhibaatooyinka gudniinka. Laga soo bilaabo 2011 iyo wixii ka danbeeyay, kumanaan haween ah ayaa ka ladnaaday dhibaatooyinka caafimaad iyo cawaaqibta khatarta ah ee la xiriira gudniinka gabdhaha iyagoo ka qayb qaatay fadhiyada talo-siinta ee xarumaha mashruuca. Wax yar kaddib booqashadan, waxaa lagu casuumay inay ka qayb-qaataan kulamada kooxaha bulshada si ay ula wadaagaan waayo aragnimadooda dumarka kale oo iyaguna helay daryeelka iyo la talinta gudniinka iyo kooxo kale ee bulshada.

Ujeedada maqaalku waa in lagu sharraxo qaabhawleedkan shaqo ee isugu dhafan ka-daryeelidda dhibaatada gudniinka gabdhaha iyo wadahadalka bulshada ee dhanka talo-bixinta. Maqaalku asal ahaan waa sharraxaad la adeegsanayo indho indhaynta qorayaasha iyo la kulankooda macaamiisha mashruuca iyo shaqaalaha oo socday in ka badan 8 sannadood. Waxaanu sidoo kale adeegsanay natiijooyin laga helay saddex buug-qoraaleed oo ku saabsan geedi-socodka iyo daraasado kale oo yar yar si loo muujiyo fahamka dadka, waayo-aragnimadooda iyo ra'yigooda ku saabsan hormarinta caafimaadka.

Casharka laga bartay mashruucan NAFIS ayaa ah iney gacan ka gaysteen furitaanka goobo lagu xiriiriyo xubnaha bulshada, kuna wada hadlaan oo khibradaha ku wadaagaan, kuna abuuraan is-faham ku saabsan dhibaatada uu keenay gudniinka gabdhuhu iyadoo aan cambaareyn dhaqan ama ceebeyn lagu saleyn. Waxaan ku falanqeynaynaa geedi-socodkaan isbeddelka aragtiyaha la xiriira deegaanka iyo ficilada dhaqanka. Caqabadda ugu weyn intii lagu guda jiray hawshan waxay ahayd ka qayb galinta ragga hawlaha la xiriira macluumaadka iyo talo-bixinta gudniinka gabdhaha. Doorka kalkaaliyayaasha/umulisooyinka oo ah kuwa ugu horreeya ee la kulma haweenka ku dhibaataysan gudniinka fircooniga ah ayaa laga dooday halkaas oo lagu adkeeyey in la xoojiyo awoodda kooxdan shaqaale caafimaad. Nooc ka mid ah gudniinka gabdhaha ayaa khalad ahaan loo adeegsadaa inuu yahay gudniin "sunno" ah oo khatartiisa caafimaad aaney caddayn.

\section{Acknowledgments}

Our thanks go first to the many women we met at the Model Centres who have openly shared their FGM experiences and concerns, and to the health workers who have taken of their valuable time to show us their work. Our special thanks go to Ugaso Jama Gulaid, former Director General of NAFIS, initiator of the project's first Support Center; Anab Ahmed, previous Director of Magan Hospital, expert on the marginalized IDP women's health problems; Shadia Ahmed Elmi, moderator in group meetings and assisting FGM survivors through the referral chain; Khadra Omer Hassan, current chairperson of NAFIS and defender of girls' and women's rights, and all other staff making NAFIS an inspiring group to work with. 


\section{About the authors}

Annika Johansson: Senior social science researcher, retired from Dept. of Global Public Health, Karolinska Institutet, Sweden; Abdirahman Osman Gaas: Executive Director of the Network against Female Genital Mutilation in Somaliland (NAFIS); Amina Mahmoud Warsame: Senior social scientist and former Chairperson of the Board of NAFIS.

\section{Author contributions}

AJ wrote the first draft and shared with the two coauthors for scrutiny and approval. AOG and AMW have in their capacities as current executive director of NAFIS and former Chairperson of NAFIS respectively, contributed to the article with information to and in discussions with A.J.

\section{Disclosure statement}

No potential conflict of interest was reported by the authors.

\section{Ethics and consent}

For the two Master's Theses by Sarah Fried and Elisabeth Isman respectively, ethical clearances were obtained from the Ethical Committee at Karolinska Institutet, Stockholm. The joint Master's thesis by Samira Warsame and Ifrah Mohamed obtained its ethical clearance from the Ethical Committee of the Ministry of Health in Somaliland. All interviews, both individual and in groups, as well as the group discussions, were held after the purpose of them had been explained and verbal consent obtained.

\section{Funding information}

For economic support to the NAFIS project over the last ten years, we are grateful to the Swedish NGO umbrella organisation ForumCiv and the Swedish International Development Cooperation Agency (Sida).

\section{Paper context}

Four decades of campaigns against female genital mutilation among the Somali population at the Horn of Africa have had little impact on prevalence rates which remain at 98-99\%. Most FGM-related research from this area is quantitative, measuring prevalence, attitudes and intended behaviour. We argue for intervention studies on participatory, communicative processes where women and men come to understand the harm caused by FGM. Measuring impact of such interventions is a challenge for research.

\section{References}

[1] UNICEF, Female genital mutilation (FGM). [cited 2021 April]. Available from: https://data.unicef.org/ topic/child-protection/female-genital-mutilation/

[2] United Nations. Intensifying global efforts for the elimination of female genital mutilation. Resolution 73/149, United Nations General Assembly 2018

[3] Weny K, Silva R, Snow R, Legesse B, Diop N. Towards the elimination of FGM by 2030: A statistical assessment. PLoS ONE 2020;15(10). Available from: https://doi.org/10.1371/journal.pone.0238782

[4] UNICEF Somalia and Somaliland Ministry of Planning and National Development, Somaliland Multiple Indicator Cluster Survey 2011, Final Report. Nairobi, Kenya: UNICEF, Somalia and Somaliland Ministry of Planning and National Development, Somaliland; 2014

[5] NAFIS. Assessment of prevalence, perception and attitude of FGM in Somaliland, 2014. Follow-up prevalence survey 2019, annexed to the previous report. Hargeisa: NAFIS Report; 2019.

[6] Central Statistics Department, Ministry of Planning and National Development, Somaliland Government. The Somaliland Health and Demographic Survey 2020. Available from: https://somalia.unfpa.org/sites/ default/files/pub-pdf/slhds2020_report_2020.pdf

[7] WHO. Types of female genital mutilation. 2021. [cited 2021 April]. Available from: https://www.who.int/ news-room/fact-sheets/detail/ female-genital-mutilation

[8] WHO. Guidelines on the management of health complications from female genital mutilation. Geneva: WHO ; 2016. Available from:https://www.who.int/ reproductivehealth/topics/fgm/management-healthcomplications-fgm/en/

[9] Ministry of Religious Affairs, Somaliland. Fatwa promulgated in 2018. Hargeisa: NAFIS, unofficial translation; 2021.

[10] Warsame A M. Female genital cutting. Transition from infibulation to smaller cutting in Somaliland. Hargeisa: NAFIS, Research Report; 2011.

[11] Gele AA, B $\varnothing$ PB, Sundby J. Attitudes toward Female Circumcision among Men and Women in Two Districts in Somalia: Is It Time to Rethink Our Eradication Strategy in Somalia? Obstetrics and Gynecology International. 2013; https://doi. org/10.1155/2013/312734

[12] Wikipedia. Female Genital Mutilation laws by country. Wikipedia; [ cited 2021 April].

[13] Edna Aden Hospital, Hargeisa. Website. [cited 2021 April]. Available from https://www.ednahospital.org/ hospital-mission/

[14] Fried S, Warsame AM, Isman E, Berggren V, Johansson A. Outpatients' Perspectives on Problems and Needs Related to Female Genital Mutilation/ Cutting: A Qualitative Study from Somaliland. (Article based on Fried's Master's Thesis). Obstetrics and Gynecology International. 2013; https://doi. org/10.1155/2013/165893

[15] Isman E, Warsame A M Fried S, Johansson A, Berggren V. Midwives Experiences in Providing Care and Counselling to Women with Female Genital Mutilation (FGM) and Related Problems. (Article based on Isman's Master's Thesis). Obstetrics and Gynecology International. 2013; https://doi. org/10.1155/2013/785148

[16] NAFIS. Audiotaped, transcribed and translated group discussion. Hargeisa; NAFIS, project report; 2014

[17] NAFIS. Notes from group interviews on social attitudes towards FGM/C in Somaliland. Awdal Region. Hargeisa: NAFIS project report; 2014.

[18] Warsame S O, Mohamed I. An assessment of women's knowledge, attitudes and experiences in the transition of ending FGM practices in Awdal Region, Somaliland. Master's thesis from College of Health Sciences, University of Hargeisa, and Nursing 
Department, Högskolan Dalarna, Sweden; 2015.

[19] NAFIS. Workshop with local, regional and national health authorities to assess project performance and sustainability. Hargeisa: NAFIS Workshop Report; 2018.

[20] Bjälkander O, Grant D S, Berggren V, Bathija H, Almroth L. Female Genital Mutilation in Sierra Leone: Forms, Reliability of Reported Status, and Accuracy of Related Demographic and Health Survey Questions. Obstetrics and Gynecology International. 2013; https:// doi.org/10.1155/2013/680926

[21] Hazel R B, Brown K, Alhassan Y, Leye E. Transforming social norms to end FGM in the EU: an evaluation of the REPLACE Approach. Reproductive Health. 2020; 17 (1); article no 40.

[22] Shell-Duncan B, Herniund Y. Are There "Stages Of Change" in The Practice Of Female Genital Cutting? Qualitative Research Findings from Senegal and The Gambia. African Journal of Reproductive Health. 2006; 10(2).

[23] Wicks PG, Reason P. Initiating action Research Challenges and paradoxes of opening communicative space. Action Research. 2009;7 (3): 243-262.

[24] Alem E, Hailu E, Siyoum H, Sesay I, Mitik L, Suyama $\mathrm{M}$ et al: Evaluation of progress with using community conversation as a strategy to encourage district level abandonment of female genital mutilation and/or cutting in 10 districts in Ethiopia. African Evaluation Journal. $2013 ; 1(1)$

[25] Newell-Jones K. Empowering communities to collectively abandon FGM/C in Somaliland. Baseline Research Report. ActionAid, Orchid Project; 2016. https://www.orchidproject.org/

[26] Askew I. Methodological issues in measuring the impact of interventions against female genital cutting. Culture Health \& Sexuality, 2005;7(5): 463-477.

[27] NAFIS. Women's stories before and after surgical treatment against the FGM complications from which they had suffered. Hargeisa: NAFIS, collected case stories from Annual Reports 2013 - 18.

[28] Ahlberg BM, Warsame AM, Johansson A, Osman Gaas, A. Engaging survivors of female genital mutilation/ cutting as Ambassadors of Change. Submitted to Somali Health Action Journal 2020.

[29] Mohamed Y, Matanda, DJ, Powell RA. Exploring the capacity of the Somaliland healthcare system to manage female genital mutilation/cutting-related complications and prevent the medicalization of the practice: a cross-sectional study. BMC Health Services Research.2020;20(1); https://doi.org/10.1186/ s12913-020-5049-2

[30] UNFPA. Millions more cases of violence, child marriage, female genital mutilation, unintended pregnancy expected due to the COVID-19 pandemic. UNFPA News; 28 April 2020. https://www.unfpa.org/news/ millions-more-cases-violence-child-marriage-femalegenital-mutilation-unintended-pregnancies

[31] Komba E. The dilemma: female genital mutilation in the midst of COVID-19 pandemic End FGM European Network; 2 April 2020. https://www.endfgm.eu/ news-en-events/news/ covid-19-pandemic-putting-girls-at-high-risk-of-fgm-inkenya/ 